\title{
Consórcio de Urochloas com milho em sistema plantio direto
}

\author{
Intercropping of pasture with maize in the no tillage system
}

\author{
Carlos Alessandro Chioderoli ${ }^{\mathrm{I}}$ Luiz Malcolm Mano de MelloII Henrique Vinicius de Holanda ${ }^{\mathrm{III}}$ \\ Carlos Eduardo Angeli Furlani ${ }^{\text {IV }}$ Paola Jurca Grigolli"II José Oscar da Rocha Silva ${ }^{\text {III }}$ \\ Andre Luis Cesarin ${ }^{\mathrm{III}}$
}

\section{RESUMO}

Uma alternativa para suprir o aporte anual de palha exigido para manutenção do sistema plantio direto (SPD), nas regiões tropicais, é o cultivo de milho consorciado com urochloas. Com o objetivo de identificar o melhor sistema de cultivo de duas espécies forrageiras (Urochloa brizantha $e$ Urochloa ruzizienses) em consórcio com o milho (Zea mays L.) em sistema plantio direto, foi realizada a presente pesquisa. O milho foi semeado em consórcio com as forrageiras em cinco sistemas de cultivo. Foi utilizado o delineamento em blocos ao acaso, em esquema fatorial $(2 x 4+1)$, com quatro repetições. Foram avaliadas: massa seca de palha do milho, massa seca da palha de urochloa, massa seca total de palha, população de plantas de milho, massa de 1000 grãos e produtividade de grãos. Os resultados demonstraram que o consórcio de milho com urochloa não apresentou efeito negativo na produtividade do milho e incrementou o aporte de matéria seca no sistema de produção sob plantio direto. A escolha de determinado sistema de cultivo depende do gerenciamento e da disponibilidade de máquinas, visto que todos os sistemas apresentaram comportamento positivo em relação à produtividade de grãos e à produção de palhada.

Palavras-chave: palhada, cobertura do solo, rotação de culturas.

\section{ABSTRACT}

An alternative to supply the annual input of straw required to maintain the no-tillage system (SPD) in the tropics is the cultivation of maize intercropped with Urochloa. In order to identify the best cropping system of two forage species (Urochloa brizantha and Urochloa ruzizienses) intercropped

\begin{abstract}
with maize (Zea mays L.) in no tillage system, the present study was conducted. Maize was seeded intercropped with forage in five cropping systems. The experimental design was in randomized blocks in factorial scheme $(2 \times 4+1)$ with four replications. There were evaluated: dry mass of maize straw, dry mass of urochloa straw, total dry mass of straw, maize plant population, mass of 1000 grain and grain yield. The results showed that maize intercropped with urochloa had no negative effect on grain yield and increased the input of dry matter in the production system under no-tillage system. The choice of a particular cropping system depends on the management and availability of machines, since all systems showed positive behavior in respect of grain yield and straw production.
\end{abstract}

Key words: straw, soil cover, crop rotation.

\section{INTRODUÇÃO}

Nas condições edafoclimáticas das regiões tropicais, é restrito o portfólio de culturas anuais economicamente viáveis. Essas condições dificultam a manutenção da estabilidade do sistema plantio direto (SPD), pois é necessário o manejo rotacionado de culturas, visando, dentre outros fatores, à formação de palha. Portanto, o sistema de integração lavourapecuária (ILP), além de proporcionar maiores quantidades de palha, pode melhorar as condições físicas do solo, bem como a produtividade das culturas semeadas sobre esse sistema.

\footnotetext{
'Programa de Pós-graduação em Ciência do Solo, Universidade Estadual Paulista "Julio Mesquita Filho" (UNESP), Faculdade de Ciências Agrárias e Veterinárias (FCAV), 14884-900, Jaboticabal, SP, Brasil. E-mail: ca.chioderoli@uol.com.br. Autor para correspondência.

"UNESP, Faculdade de Engenharia de Ilha Solteira (FEIS), Ilha Solteira, SP, Brasil.

"'Curso deAgronomia, FEIS, Ilha Solteira, SP, Brasil.

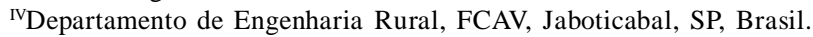


O SPD associado à integração lavourapecuária é uma alternativa de manejo que concilia a manutenção, e até mesmo a elevação da produção, com maior racionalidade dos insumos empregados (SANTOS et al., 2008). Segundo os autores, o sucesso desses sistemas no cerrado brasileiro deve-se ao fato de que a palhada proporciona um ambiente favorável à recuperação ou manutenção das propriedades do solo. Além disso, ocorre o aumento da matéria orgânica no solo, proporcionando melhoria na sua qualidade (CONCEIÇÃO et al., 2005), em função de sua agregação, com reflexos positivos na partição da água, favorecendo a infiltração e diminuindo o escoamento superficial.

A escolha de culturas anuais economicamente viáveis e adaptadas ao consórcio com forrageiras é uma característica necessária para o sucesso do sistema produtivo. $\mathrm{O}$ milho tem se destacado como uma das principais explorações agrícolas no Brasil, não apenas pela área cultivada, mas também pela importância econômica e social. A adoção de sistemas de ILP tem se expandido nos cerrados, principalmente após o advento do Sistema Santa Fé, desenvolvido para disponibilização de forragem verde na época mais seca do ano. De acordo com CUNHA et al. (2007), esse sistema consiste na consorciação de culturas de grãos, especialmente o milho, sorgo e arroz, com forrageiras tropicais, principalmente as do gênero Urochloa. Nesse sistema, as espécies de Urochloa são consorciadas com milho, sem prejuízo para a cultura anual, além da produção de forragem para entressafra, possibilitando ainda a obtenção de palhada de alta qualidade, adequada à condução do SPD em condições tropicais (GÖRGEN et al., 2010).

Portanto, o consórcio, quando praticado de maneira tecnicamente correta, proporciona o aumento da quantidade de palha, visando à melhor cobertura do solo para a realização da semeadura direta e muitas vezes o aumento de produtividade na cultura sequente e/ou a antecipação da formação de pastagem (CHIODEROLI et al., 2010). Com isso, é necessário o conhecimento da espécie vegetal a ser utilizada no programa de rotação ou consorciação de culturas quanto à sua produção de massa seca e tempo de decomposição, que interferem diretamente na quantidade de palha sobre o solo (ANDREOTTI et al., 2008).

Espécies forrageiras perenes como Urochloa decumbens, U. brizantha, Panicum maximum cv. 'Tanzânia' e P. maximum cv. 'Mombaça', além de fornecerem grande quantidade de massa seca, que é fundamental para o SPD, apresentam alta relação carbono/nitrogênio $(\mathrm{C} / \mathrm{N})$, retardando a velocidade de decomposição da palha, aumentando a possibilidade de utilização em regiões mais quentes e favorecendo a proteção do solo contra erosão e radiação solar
(TIMOSSI et al., 2007). As espécies do gênero Urochloa, de maneira geral, vêm sendo consideradas opções proeminentes na formação da palhada para o SPD, devido à boa produção de massa seca e à alta relação C/N de sua composição (NUNES et al., 2006).

Assim, para manter anualmente o aporte de palha exigido para manutenção da estabilidade do SPD, o consórcio de milho com forrageiras pode ser uma alternativa viável, sendo necessário identificar qual o melhor sistema de cultivo e a melhor forrageira a ser utilizada. Com isso, o presente trabalho teve como objetivo avaliar o melhor sistema de cultivo de duas espécies forrageiras (Urochloa brizantha e Urochloa ruzizienses) em consórcio com o milho, em sistema plantio direto.

\section{MATERIAL E MÉTODOS}

O experimento foi instalado no ano agrícola de 2009 em área pertencente à Faculdade de Engenharia de Ilha Solteira - UNESP, com as coordenadas geográficas de referência $20^{\circ} 20^{\prime} \mathrm{S}$ e $51^{\circ} 24^{\prime} \mathrm{W}$, a altitude local de $350 \mathrm{~m}$ com $4 \%$ de declividade. O solo foi classificado, segundo DEMATTÊ (1980), como LATOSSOLO VERMELHO Escuro epieutrófico/ endoálico, textura argilosa, apresentando declividade média de $4 \%$ e boa drenagem, correspondendo à nova classificação brasileira como LATOSSOLO VERMELHO Distroférrico, textura argilosa (EMBRAPA, 2006). Aárea experimental é manejada em sistema de plantio direto há oito anos e apresentava a soja como cultura antecessora.

A parcela experimental foi de $180 \mathrm{~m}^{2}$, constituída de oito linhas de milho, espaçadas de $0,90 \mathrm{~m}$ e com $25 \mathrm{~m}$ de comprimento, com carreadores de $10 \mathrm{~m}$ para manobras das máquinas e implementos, e carreadores de $1 \mathrm{~m}$ para separação dos blocos experimentais. Utilizou-se o delineamento em blocos ao acaso, com nove tratamentos em esquema fatorial $2 \times 4+1$, com quatro repetições. Aárea útil avaliada para determinação da massa seca da palha do milho, massa seca das forrageiras, massa seca total de palha, população de plantas, massa de 1000 grãos e produtividade de grãos utilizando-se as duas linhas centrais, com $5 \mathrm{~m}$ cada.

Os tratamentos foram constituídos por duas espécies de urochloas (Urochloa brizantha e Urochloa ruzizienses) e cinco modalidades de consórcio das urochloas com o milho: Milho com urochloa na linha de semeadura, sendo a urochloa misturada ao adubo de base e depositada a $0,10 \mathrm{~m}$ e ao lado da semente de milho (MBL); Milho com urochloa na entrelinha, semeada na entrelinha no mesmo dia da 
semeadura do milho, com a presença de uma linha de semeadura intermediária (MBE); Milho com urochloa na entrelinha semeada junto com o adubo de cobertura no estádio $\mathrm{V}_{4}$ (MBC); Milho com urochloa a lanço na época de adubação de cobertura (MBLA); TESTEMUNHA- (Milho Solteiro - MS).

Foram utilizados os equipamentos agrícolas: trator de pneus (4x2 TDA), com potência máxima de $77,28 \mathrm{~kW}$ no motor; trator de pneus (4x2), com potência máxima de 54,4kW no motor; adubador de cobertura para plantio direto, com largura de chassi $2,30 \mathrm{~m}$ e quatro discos de corte duplos desencontrados de diâmetro (13"x15") e dois depósitos com capacidade de 2201; semeadora-adubadora de arrasto, com sistema pneumático de dosagem de sementes, configurada para semeadura direta com disco de corte frontal, sulcador de haste para deposição do adubo e discos duplos desencontrados para deposição de sementes, rodas controladoras de profundidade paralelas e rodas compactadoras em "V".

Utilizaram-se sementes do milho híbrido simples precoce de marca comercial DKB 390, visando a uma população de $60 \mathrm{mil}$ plantas ha ${ }^{-1}$, com espaçamento entrelinhas de $0,90 \mathrm{~m}$, densidade de semeadura de 5,4 sementes $\mathrm{m}^{-1}$, semeado no dia $05 / 06 / 2009$, e tratadas com o produto Tiodicarbe, na dose de $600 \mathrm{~g}$ do ingrediente ativo (i.a) para cada 100kg semente. Na consorciação, foram utilizados $10 \mathrm{~kg} \mathrm{ha}^{-1}$ de cada forrageira, com sementes certificadas de Urochloa brizantha cv. Marandue Urochloa ruzizienses, ambascom, valor cultural de $76 \%$. Para adubação de base do milho, foi utilizado $350 \mathrm{~kg} \mathrm{ha}^{-1}$ da fórmula comercial (08-28-16), e, para adubação de cobertura, com o milho no estádio $\mathrm{V}_{4}$, foram aplicados $120 \mathrm{~kg} \mathrm{ha}^{-1}$ de cloreto de potássio e $300 \mathrm{~kg}$ $\mathrm{ha}^{-1}$ de ureia. Para as forrageiras, utilizaram-se $20 \mathrm{~kg} \mathrm{ha}^{-1}$ da fórmula comercial (08-28-16) para semeadura na entrelinha e na época de cultivo do milho (10/07/2009), sendo que o adubo foi utilizado somente como veículo de distribuição das sementes.

A determinação da massa seca de palha do milho foi obtida pela pesagem de todas as plantas da área útil da parcela, com desconto, após a trilha, do peso dos grãos, obtendo-se o peso da massa verde da palhada. Foi retirada uma amostra e submetida à secagem em estufa com circulação forçada de ar, por $72 \mathrm{~h}$ a $65^{\circ} \mathrm{C}$, determinando-se a $\%$ de água e, posteriormente, realizou-se o cálculo da produtividade de massa seca de palha por hectare. Para massa seca das forrageiras, utilizou-se armação de ferro com área de $0,25 \mathrm{~m}^{2}$, coletando-se quatro subamostras por parcela nos tratamentos, com a forrageira na entrelinha e a lanço, sendo que, para as forrageiras semeadas na linha, coletaram-se $2 \mathrm{~m}$ de duas linhas da área útil da parcela.
O material colhido foi pesado e uma amostra foi levada à estufa com circulação forçada de ar por $72 \mathrm{~h} \mathrm{a} 65^{\circ} \mathrm{C}$, determinando-se a massa seca para o cálculo de produção de massa seca ha-1, destacando-se que a massa seca total de palha foi obtida por meio da somatória da palhada de milho e forrageira, variável importante, pois representa a condição inicial para semeadura das culturas sequentes.

A massa de 1000 grãos foi determinada conforme metodologia proposta por BRASIL (1992). $\mathrm{Na}$ determinação da produtividade de grãos de milho $\left(\mathrm{kg} \mathrm{ha}^{-1}\right)$, foram coletadas as espigas da área útil de cada parcela e elas foram trilhadas com auxílio de trilhadora mecânica estacionária. Os grãos foram separados e pesados e os valores foram corrigidos para a base úmida de $13 \%$, baseadas nas Regras de Análise de Sementes de BRASIL (1992), e os valores transformados em $\mathrm{kg} \mathrm{ha}^{-1}$. Para a população inicial e final de plantas, foram contadas as plantas presentes na área útil de cada parcela. Os valores encontrados foram extrapolados para número de plantas ha- ${ }^{-1}$.

Os dados foram submetidos à análise de variância e, quando o valor do teste $\mathrm{F}$ foi significativo a pelo menos $10 \%$ de probabilidade, realizou-se a comparação de médias pelo teste de Tukey a 10\% de probabilidade.

\section{RESULTADOS E DISCUSSÃO}

Verificou-se que a população inicial e final de plantas, bem como a produtividade de grãos de milho, não apresentaram diferenças significativas em função dos tratamentos utilizados. Entretanto, para massa de 1000 grãos, houve efeito significativo para sistema de cultivo, sendo os maiores valores no MBL diferindo significativamente do MBC, porém sendo iguais aos demais tratamentos (Tabela 1). Esses resultados demonstram que a massa de 1000 grãos, associada ao número final de plantas e à prolificidade das plantas, é um importante componente da produtividade de grãos, podendo ser afetada por qualquer tipo de estresse que a planta sofra após o florescimento. Apesar da maior competição proporcionada pelas forrageiras semeadas na linha, o milho apresentou os maiores valores de massa de 1000 grãos, provavelmente, devido ao maior acúmulo de nutrientes nos grãos, provocado pela competição interespecífica nesse sistema de cultivo (MBL).

De acordo com FANCELLI \& DOURADO NETO (2000), o potencial produtivo do milho é definido precocemente, ou seja, por ocasião da emissão da quarta folha, podendo se estender até a sexta folha, principalmente em função da diferenciação da inflorescência masculina antes da inflorescência 
Tabela 1 - Valores médios de população inicial e final de plantas, massa de 1000 grãos e produtividade de grãos de milho no consórcio de urochloas com milho em diferentes sistemas de cultivo.

\begin{tabular}{|c|c|c|c|c|c|}
\hline & & \multicolumn{4}{|c|}{ - } \\
\hline Causas de Variação & & $\begin{array}{l}\text { População Inicial } \\
\text { (Plantas ha }^{-1} \text { ) }\end{array}$ & $\begin{array}{l}\text { População Final } \\
\left.\text { (Plantas ha }{ }^{-1}\right)\end{array}$ & $\begin{array}{l}\text { Massa de } 1000 \text { Grãos } \\
(\mathrm{kg})\end{array}$ & $\begin{array}{l}\text { Produtividadede Grãos } \\
\qquad\left(\mathrm{kg} \mathrm{ha}^{-1}\right)\end{array}$ \\
\hline \multirow{2}{*}{ Forrageiras (F) } & U. brizantha & 55000 & 51597 & 0,322 & 5644 \\
\hline & U. ruzizienses & 54097 & 53194 & 0,329 & 5069 \\
\hline \multirow{5}{*}{ Sistema de Cultivo (SC) } & MBL & 55139 & 53056 & $0,334 \mathrm{a}$ & 5382 \\
\hline & MBE & 54722 & 51806 & $0,327 \mathrm{ab}$ & 5192 \\
\hline & MBC & 54722 & 52222 & $0,316 b$ & 5299 \\
\hline & MBLA & 53611 & 52500 & $0,326 a b$ & 5552 \\
\hline & MS & 56667 & 53333 & $0,329 \mathrm{ab}$ & 5843 \\
\hline \multirow{3}{*}{ Valor de F } & $\mathrm{F}$ & $0,824^{\mathrm{NS}}$ & $1,128^{\mathrm{NS}}$ & $1,607^{\mathrm{NS}}$ & $1,642^{\mathrm{NS}}$ \\
\hline & $\mathrm{SC}$ & $0,481^{\mathrm{NS}}$ & $0,233^{\mathrm{NS}}$ & $2,513^{*}$ & $0,329^{\mathrm{NS}}$ \\
\hline & $\mathrm{F}^{*} \mathrm{SC}$ & $1,422^{\mathrm{NS}}$ & $1,779^{\mathrm{NS}}$ & $0,785^{\mathrm{NS}}$ & $1,542^{\mathrm{NS}}$ \\
\hline \multirow{2}{*}{ DMS } & $\mathrm{F}$ & 3980,125 & 3480,912 & 0,013 & 1110,335 \\
\hline & $\mathrm{SC}$ & 5280,757 & 4618,409 & 0,017 & 1473,171 \\
\hline $\mathrm{CV}(\%)$ & & 6,74 & 6,15 & 3,61 & 19,04 \\
\hline
\end{tabular}

Médias seguidas de letras distintas nas colunas diferem entre si pelo teste de Tukey $(\mathrm{P}<0,1)$. MBL: Milho consorciado com urochloa na linha; MBE: Milho consorciado com urochloa na entrelinha; MBC: Milho consorciado com urochloa em cobertura no estádio $\mathrm{V}_{4}$; MBLA: Milho consorciados com urochloa a lanço em $\mathrm{V}_{4}$; e MS: Testemunha. ${ }^{\text {NS}}$ : não significativo; CV: coeficiente de variação (\%).

feminina. Contudo, é importante ressaltar que as características que estão relacionadas com a produtividade de grãos podem ser afetadas por qualquer tipo de estresse da planta nessas fases. Para os valores de produtividade de grãos, não houve efeito significativo $(\mathrm{P}<0,1)$ em função dos tratamentos utilizados, mostrando que o MS, assim como os tratamentos em consórcio, apresentaram valores iguais de produtividade de grãos, justificando a utilização do consórcio, pois, além de obter produtividades semelhantes, é possível aumentar a quantidade de palha exigida para manutenção do SPD, sem afetar de maneira significativa a produtividade, sendo o sistema de cultivo e a forrageira a ser utilizada dependente do ponto de vista gerencial e operacional.

Esses resultados discordam dos obtidos por MELLO et al. (2007), que, trabalhando com consórcio de U. brizantha e milho, na mesma região e tipo de solo, detectaram a interferência exercida pela forrageira sobre o milho, quando consorciada na linha de semeadura e à lanço em área total, no mesmo dia da semeadura do milho. Os resultados mostraram que essas modalidades de consórcio afetaram o desenvolvimento do milho, reduzindo a produtividade de grãos, quando comparados com a produtividade obtida no tratamento de milho solteiro. Resultados contrários também foram encontrados por CHIODEROLI et al. (2010), avaliando o consórcio de milho com três espécies forrageiras semeadas em três sistemas de cultivo, os quais verificaram que a maior produtividade de grãos de milho foi obtida no consórcio de milho com urochloa no cultivo $\left(\mathrm{V}_{4}\right)$, sendo que os tratamentos com $\boldsymbol{U}$. ruzizienses apresentaram maiores valores de produtividade de grãos.

De acordo com KOZLOWSKI et al. (2009), no consórcio efetuado na época de cobertura, a competitividade é menor, porque o milho ultrapassa o período crítico de interferência (PCPI), que corresponde a um período de nove dias após a emergência, ou seja, estádio fenológico $\mathrm{V}_{2}$ (duas folhas expandidas), período em que a cultura pode conviver com as plantas daninhas sem que ocorra redução significativa na sua produtividade. Já resultados mostrados por BORGHI \& CRUSCIOL (2007) afirmaram que a consorciação de milho com urochloa promoveu, em média, menores produtividades de grãos de milho, discordando dos resultados obtidos neste trabalho, em que não houve interferência das forrageiras em função das modalidades de consórcio. 
A avaliação da produtividade de massa seca de palha é fundamental para optar por sistemas de cultivos que promovam maior quantidade de palha sem afetar a produtividade de grãos, uma vez que a massa seca total de palha é uma variável importante a ser analisada, pois representa a condição inicial para semeadura das culturas em sucessão. Conforme a tabela 2, verifica-se que houve efeito significativo pelo teste de Tukey $(\mathrm{P}<0,1)$ para massa seca da palha do milho e massa seca das forrageiras, em função do tratamento "sistema de cultivo", e, para massa seca total de palha, os resultados não apresentaram diferenças significativas para ambos os tratamentos. A maior produtividade de massa seca de palha do milho ocorreu no tratamento de milho solteiro, diferindo significativamente dos demais tratamentos, que apresentaram menores valores. Esses resultados mostram a competição que as forrageiras promovem quando semeadas em consórcio com o milho; provavelmente por água, nutrientes, luz e espaço físico. Entretanto, essa menor produtividade de palha de milho pode ser compensada pela massa seca da forrageira, fato sucedido na presente pesquisa.
Para os valores de massa seca das forrageiras, não houve efeito significativo para as forrageiras analisadas. Entretanto, para os sistemas de cultivo, os resultados mostraram que a maior produtividade de massa seca foi obtida pelo MBE, diferindo significativamente do MBLA e MS, sendo iguais aos demais tratamentos, concordando com resultados encontrados por CHIODEROLI et al. (2010). A maior produtividade de forragem na entrelinha ocorre devido à menor competição proporcionada pelo milho, quando comparada aos outros tratamentos, permitindo assim rápido desenvolvimento inicial da forrageira e maior eficiência fotossintética, convertendo em maior crescimento final, ou seja, acúmulo de matéria seca.

As forrageiras semeadas a lanço na época de adubação de cobertura do milho sofrem o efeito de sombreamento e concorrência com a cultura principal, principalmente por água, nutrientes e espaço físico, explicando a menor produtividade de massa seca da forrageira nesse tratamento (MBLA). Os dados oriundos deste trabalho concordam com JAKELAITIS et al. (2005), os quais comentam que sistemas de semeadura de $\boldsymbol{U}$. brizantha solteira, ou em linhas e a lanço, em consórcio com o milho, influenciam fortemente na produção de forragem.

Tabela 2 - Valores médios de massa seca de palha do milho, de palha de urochloa e massa seca total de palha no consórcio de urochloas com milho, em diferentes sistemas de cultivo.

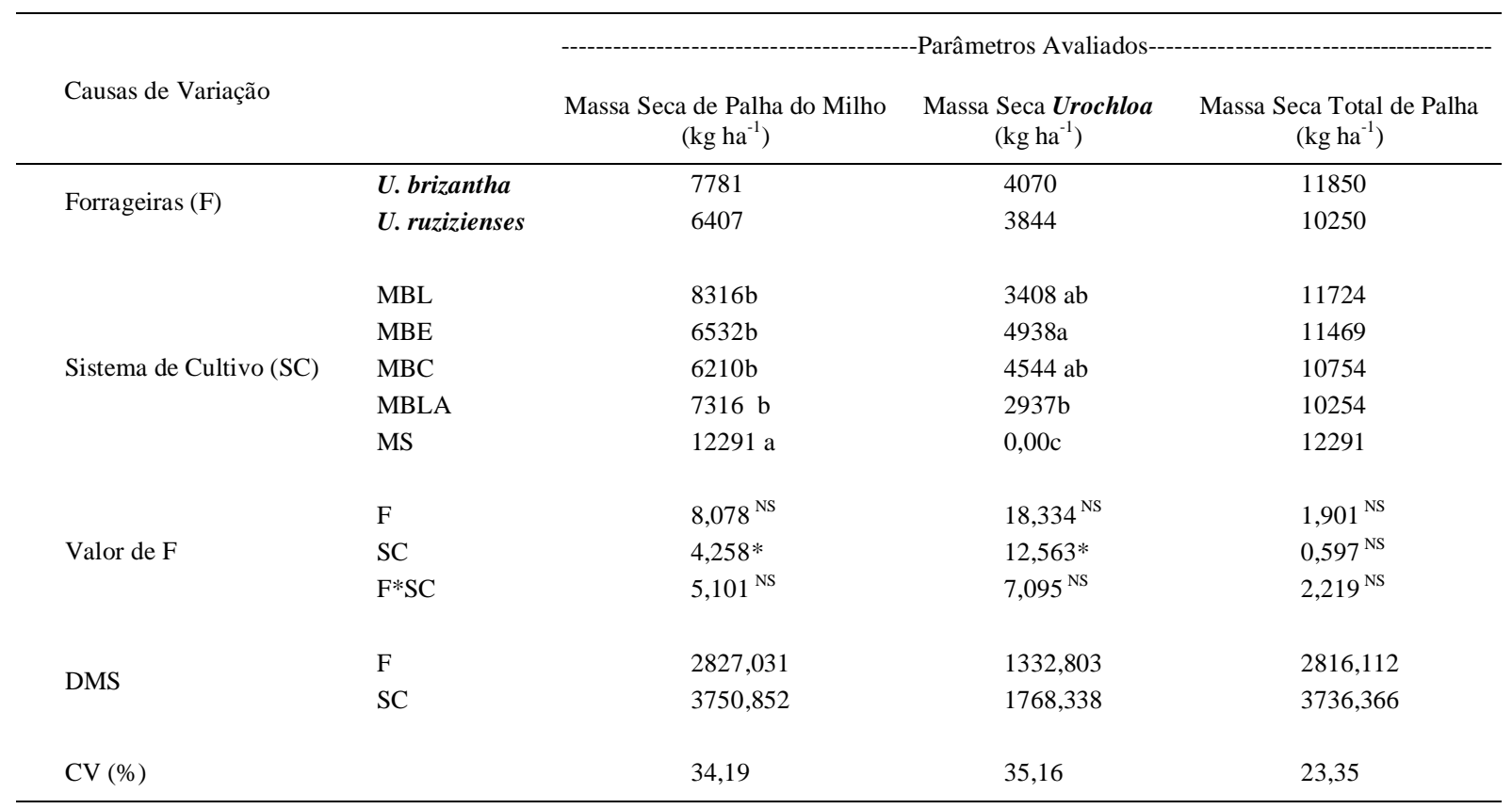

Médias seguidas de letras distintas nas colunas diferem entre si pelo teste de Tukey $(\mathrm{P}<0,1)$. MBL: Milho consorciado com urochloa na linha; MBE: Milho consorciado com urochloa na entrelinha; MBC: Milho consorciado com urochloa em cobertura no estádio V4; MBLA: Milho consorciado com urochloa a lanço em $\mathrm{V}_{4}$; e MS: Testemunha. ${ }^{\mathrm{NS}}$ : não significativo; CV: coeficiente de variação (\%). 
A produção de massa seca de palha total não apresentou diferença significativa entre os tratamentos. Esses resultados mostram que os menores valores de massa seca da palha do milho são compensados pela quantidade de palha produzida pelas forrageiras, sendo que, independentemente da espécie forrageira e do sistema de cultivo utilizado, o aporte total de palha foi igual para todos os tratamentos (Tabela 2). Portanto, os valores mostraram que foram suficientes para suprir a quantidade de palha que deve ser adicionada anualmente à superfície do solo, para que o SPD tenha plenas condições de manifestar o seu potencial como sistema sustentável, sendo esse aporte anual de resíduos, segundo AMADO (2000), da ordem de 10 a $12 \mathrm{Mg} \mathrm{ha}^{-1}$.

A escolha da espécie forrageira vai depender da finalidade do consórcio, seja para formação de pastagem ou para produção de palhada para o SPD, sendo que MACHADO \& ASSIS (2010) concluíram que as forrageiras Urochloa ruziziensis e Urochloa decumbens, por se manterem em crescimento durante toda a estação seca e pela facilidade de dessecação, podem ser melhor aproveitadas com o propósito de cobertura do solo. Do ponto de vista operacional, o consórcio do MBLé o mais viável, além do menor custo de implantação, entretanto, é necessário o acompanhamento anual, pois, em virtude das mudanças climáticas, podem alterar a formação de palha, bem como a produtividade de grãos.

Conforme ALLEN et al. (2007) e FRANZLUEBBERS (2007), os resultados desse sistema refletem os avanços nos aspectos de tecnologia, gestão, produtividade e incremento de lucratividade. De acordo com SULC \& TRACY (2007) e MAUGHAN et al. (2009), ainda há uma necessidade de financiamentos para novas pesquisas com o intuito de abordar melhor as consequências da integração agricultura-pecuária no complexo socioeconômicoambiental. Vale ressaltar também a importância de se avaliar o sistema como um todo, com um planejamento de sucessão/rotação de culturas adequado para garantir a sustentabilidade do SPD e integrar sistemas que envolvam lavoura e pecuária (PARIZ et al., 2009), além da escolha de sistemas de cultivo com menor custo de implantação, visando à maior lucratividade do sistema produtivo.

\section{CONCLUSÃO}

O consórcio de milho com urochloas não alterou a produtividade do milho e incrementou o aporte de massa seca no sistema de produção sob plantio direto. $\mathrm{O}$ sistema de cultivo com semeio de milho com urochloa na linha de semeadura, com a urochloa misturada ao adubo de base e depositada a $0,10 \mathrm{~m}$ e ao lado da semente de milho é o mais prático, do ponto de vista operacional; sendo que todos os sistemas estudados produziram palha em quantidade suficiente para a manutenção do sistema de semeadura direta.

\section{AGRADECIMENTOS}

Fundação de Amparo à Pesquisa do Estado de São Paulo (FAPESP), pela concessão da bolsa de Doutorado ao primeiro autor.

\section{REFERÊNCIAS}

ALLEN, V.G. et al. Integrated irrigated crop-livestock systems in dry climates. AgronomyJournal, Madison, v.99, n.2, p.346$360,2007$.

AMADO, T.J. Manejo da palha, dinâmica da matéria orgânica e ciclagem de nutrientes em plantio direto. In: ENCONTRO NACIONAL DE PLANTIO DIRETO NA PALHA, 7., 2000, Foz do Iguaçu, PR. Resumos... Foz do Iguaçu: F.B.P.D.P., 2000. p.105-111.

ANDREOTTI, M. et al. Produtividade do milho safrinha e modificações químicas de um latossolo em sistema plantio direto em função de espécies de cobertura após calagem superficial. Acta ScientiarumAgronomy, Maringá, v.30, n.1, p.109-115, 2008.

BRASIL. Ministério da Agricultura e Reforma Agrária. Secretária de Defesa Agropecuária. Departamento Nacional de Defesa Vegetal. Regras para análise de sementes. Brasília, 1992. 365p.

BORGHI, E.; CRUSCIOL, C.A.C. Produtividade de milho, espaçamento e modalidade de consorciação com Brachiaria brizantha no sistema plantio direto. Pesquisa Agropecuária Brasileira, Brasília, v.42, n.2, 163-171, 2007. Disponivel em: <http:// dx.doi.org/10.1590/S0100-204X2007000200004>. Acesso em: 01 maio, 2011. doi: 10.1590/S0100-204X2007000200004.

CHIODEROLI, C.A. et al. Consorciação de braquiárias com milho outonal em plantio direto sob pivô central. Engenharia Agrícola, Jaboticabal, v.30, n.6, p.1101-1109, 2010. Disponível em: <http:/ /dx.doi.org/10.1590/S0100-69162010000600011>. Acesso em: 01 maio, 2011. doi: 10.1590/S0100-69162010000600011.

CONCEIÇÃO, P.C. et al. Qualidade do solo em sistemas de manejo avaliada pela dinâmica da matéria orgânica e atributos relacionados. Revista Brasileira de Ciência do Solo, Viçosa, 29, n.5, p.777-788, 2005. Disponível em: <http://dx.doi.org/ 10.1590/S0100-06832005000500013 >. Acesso em: 10 maio, 2010. doi: 10.1590/S0100-06832005000500013.

CUNHA, E.Q. et al. Influência de rotações de culturas nas propriedades físico-hídricas de um Latossolo Vermelho em plantio direto. Engenharia Agrícola, Jaboticabal, v.27, n.3, p.675-682, 2007. Disponível em: <http://dx.doi.org/10.1590/ S0100-69162007000400009>. Acesso em: 10 maio, 2010. doi: 10.1590/S0100-69162007000400009.

DEMATTÊ, J.L.I. Levantamento detalhado de solos do "Campus Experimental de Ilha Solteira". Piracicaba: 
Escola Superior de Agricultura "Luiz de Queiroz", 1980. 44p. EMPRESA BRASILEIRA DE PESQUISA AGROPECUÁRIA Embrapa. Sistema brasileiro de classificação dos solos. 2.ed. Rio de Janeiro: CNPS, 2006. 306p.

FANCELli, A.L.; DOURADO NETO, D. Produção de milho. Guaíba: Agropecuária, 2000. 360p.

FRANZLUEBBERS, A.J. Integrated crop-livestock systems in the Southeastern USA. Agronomy Journal, Madison, v.99, n.2, p.361-372, 2007.

GÖRGEN, C.A. et al. Redução do inóculo inicial de Sclerotinia sclerotiorum em soja cultivada após uso do sistema santa fé. Pesquisa Agropecuária Brasileira, Brasília, v.45, n.10, p.1102-1108, 2010. Disponível em: <http://dx.doi.org/ 10.1590/S0100-204X2010001000008>. Acesso em: 04 jun. 2010. doi:10.1590/S0100-204X2010001000008.

JAKELAITIS, A. et al. Influência de herbicidas e de sistemas de semeadura de Brachiaria brizantha consorciada com milho. Planta Daninha,Viçosa, v.23, n.1, p.59-67, 2005.

KOZLOWSKI, L.A. et al. Épocas e extensões do período de convivência das plantas daninhas interferindo na produtividade da cultura do milho (Zea mays). Planta Daninha, Viçosa, v.27, n.3, p.481-490, 2009. Disponível em: <http:// www.scielo.br/pdf/pd/v27n3/08.pdf>. Acesso em: 29 maio. 2012. doi.org/10.1590/S0100-83582009000300008.

MACHADO, L.A.Z.; ASSIS, P.G.G. Produção de palha e forragem por espécies anuais e perenes em sucessão à soja. Pesquisa Agropecuária Brasileira, Brasília, v.45, n.4, p.415422, 2010. Disponível em: <http://dx.doi.org/10.1590/S0100204X2010000400010>. Acesso em: 10 abr. 2011. doi: 10.1590/S0100-204X2010000400010.
MAUGHAN, M. et al. Soil quality and corn yield under croplivestock integration in Illinois. Agronomy journal, Madison, v.101, n.6, p.1503-1510, 2009.

MELLO, L.M.M. et al. Integração agricultura-pecuária em plantio direto: consorciação braquiária e milho. In: CONGRESSO BRASILEIRO DE ENGENHARIA AGRÍCOLA, 36., 2007, Bonito. Anais... Jaboticabal: Sociedade Brasileira de Engenharia Agrícola, 2007. 1CD ROM.

NUNES, U.R. et al. Produção de palhada de plantas de cobertura e rendimento do feijão em plantio direto. Pesquisa Agropecuária Brasileira, Brasília, v.41, n.6, p.943-948, 2006. Disponível em: <http://dx.doi.org/10.1590/S0100204X2006000600007>. Acesso em: 10 abr. 2011. doi: 10.1590/S0100-204X2006000600007.

PARIZ, C.M. et al. Desempenhos técnicos e econômicos da consorciação de milho com forrageiras dos gêneros Panicum e Brachiaria em sistema de integração lavoura-pecuária. Pesquisa Agropecuária Tropical, Goiânia, v.39, n.4, p.360-370, 2009.

SANTOS, G.G. et al. Macrofauna edáfica associada a plantas de cobertura em plantio direto em um latossolo vermelho do Cerrado. Pesquisa Agropecuária Brasileira, Brasília, v.43, n.1, p.115-122, 2008. Disponível em: <http://dx.doi.org/ 10.1590/S0100-204X2008000100015 >. Acesso em: 08 abr. 2011. doi: 10.1590/S0100-204X2008000100015.

SULC, R.M.; TRACY, B.F. Integrated crop-livestock systems in the U.S. Corn Belt. Agronomy journal, Madison, v.99, n.2, p.335-345, 2007.

TIMOSSI, P.C. et al. Formação de palhada por braquiárias para adoção do sistema plantio direto. Bragantia, Campinas, v.66, n.4, p.617-622, 2007. Disponível em: <http://dx.doi.org/ 10.1590/S0006-87052007000400012>. Acesso em: 08 abr. 2011. doi: $10.1590 /$ S0006-87052007000400012. 